\title{
Research on centralized purchasing management of China's chain retail enterprises
}

\author{
Yan Wang ${ }^{1, \text { a }}$ Xiaohan $\mathrm{Gao}^{2, \mathrm{~b}}$ \\ (1Dalian University of Science And Technology , Dalian 116052)
}

Key words: chain retail enterprises; centralized procurement management

\begin{abstract}
For chain retail enterprises, the procurement process and enterprise development are closely linked. China's retail industry has huge potential, huge consumer groups and increasing consumer demand, which provide a huge market for China's retail industry. In this paper the current situation of the development of chain retail enterprises are analyzed, and pointed out that centralized purchasing mode of retail enterprises in the procurement procedures, the significance of finding out the existing problems of centralized purchasing link, and put forward the corresponding countermeasure to help retail chains to solve the problems of centralized purchasing, hoping to help domestic retail enterprises in the aspect of the optimization and improvement of the enterprise in the present economic environment better operation and development.
\end{abstract}

\section{Introduction}

As one of the traditional industries, the cost problem is always the most important and urgent enterprise problem. By strengthening the management of purchasing link, lower the cost of buying and selling of commodities circulation as far as possible, at the same time the prices of goods and keep in the enterprise, can afford the lowest price online, and then take advantage of cost savings to form hair, successfully open the market situation, quickly occupy the market share, finally obtained compared with other enterprises more profits.

In today's society, people's demands are increasingly changing, new demands are constantly generated, and at the same time, global economic market competition is unprecedentedly fierce, which directly leads to chain retail enterprises to put forward more stringent requirements on procurement. Procurement has always been an important part of the management of chain retail enterprises, and it is also an urgent part to improve the management level. It concerns the core competitiveness of chain retail enterprises. At present, after the historical development of the retail industry, it is not the traditional commodity circulation, but gradually close to the direction of supply management, and it is also the trend of gradually close to the customer demand. Therefore, it has important management value and guiding significance to carry out analysis and research on how to improve the purchasing management level of chain retail enterprises so as to achieve the purpose of helping enterprises to reduce the purchasing cost to the maximum extent and realize the improvement of core competitiveness of chain retail enterprises. 


\section{Development status of China's chain retail enterprises}

Since the reform and opening up, China's economic development has been booming all the way, driving the rapid progress of various industries in China. The retail industry has been greatly supported by the state. Beijing hualian, Shanghai lianhua and other enterprises are the fastest growing chain retail enterprises in China, and their offline stores are mainly distributed in coastal economic developed areas and large cities in China.But on the other hand, it also faces many problems in development. However, with the strong entry of foreign brands, domestic retail enterprises are constantly exposed to various problems:

First, regional development is uneven. As the developed areas in China are basically in coastal areas, chain operation enterprises are mainly distributed in cities in coastal areas. As a result, retail enterprises are reluctant to operate in western regions due to the small population, inconvenient transportation, and the limited consumption level of residents at a lower level of economy.

Second, the relationship between enterprises and suppliers is worrying. For a long time, chain retail enterprise sales profit is less, the commercial profit income mainly comes from charging slotting fees, sponsorship, bar code, supplier's benefit promotion expenses, etc., these extra costs accounted for more than $26 \%$ of sales.As a retailer, the continuous exploitation of suppliers and the expansion of mergers and acquisitions with the capital of suppliers further aggravates the relationship between them. According to the latest survey, the satisfaction of suppliers to retailers is less than $33.3 \%$ at present.

Third, the level of purchasing management needs to be improved. Commodity procurement costs occupy fifteen percent of sales ratio is even higher, so the efficiency of the high cost but procurement is still not high.

Fourth, the shortage rate is high. According to relevant data, the average shortage rate of domestic chain industry is about $10 \%$, which is much higher than that of foreign industries. The annual loss caused by goods shortage and shortage is as high as 83 billion RMB.

Fifth, the information technology transformation in the procurement process is too low. In recent years, Although many domestic chain retail stores also introduce information technology into the internal management of enterprises and improve the operating efficiency of enterprises, the level of application transformation is too shallow.

\section{Problems existing in the centralized procurement of China's chain retail enterprises.}

In 2016, China's retail sales were 29651.8 billion yuan, up by $10.4 \%$ year-on-year. The growth rate of China's retail sales was still at a relatively high level, which was $7.5,11$ and 7.6 percentage points higher than that of the United States, Japan and the European Union. However, with such a good development situation, the development of domestic chain retail enterprises is not satisfactory, with various problems occurring frequently, which causes losses to consumers and damages to the corporate image at the same time. The root cause of the problem is the purchase of goods in the link management.

\subsection{The timely supply of commodities cannot be guaranteed}

After the centralized procurement management, the information of commodity demand needs to pass through the bottom-up process, which greatly lengthens the process of commodity procurement and increases the processing and procedures of each link. At this point, once the demand information changes or problems occur, the reaction time of commodity procurement implementation is relatively long, which leads to the failure of timely supply of commodities and the corresponding delay. 


\subsection{Serious overstocking of commodities}

In the daily operation process of an enterprise, in order to better cope with the change of market demand, it is unavoidable to make partial adjustments to the procurement plan based on the consideration of the market and its own factors. Such adjustment of procurement plan will affect the actual purchase amount of commodities, which may lead to the backlog of commodities due to market changes.

\subsection{Large additional costs arising from centralized procurement}

The centralized procurement of goods is often not directly delivered to stores, but to the warehouse where goods are stored. In this mode of supply, storage and delivery costs are incurred in order to store and supply goods. Therefore, if the cost reduced by enterprises after adopting centralized procurement is not enough to offset these two additional expenditures, enterprises will gain more than they lose, which will instead cause the increase of procurement cost and unnecessary expenditure.

\subsection{Centralized procurement results in increased financial burden of enterprises}

After the implementation of the centralized procurement model, since it is often a one-time purchase of more goods, the cost of a single enterprise will be significantly increased. If the commodity sales volume is not hot all the time after that, the capital of the enterprise will be difficult to return quickly, which will inevitably lead to problems in the turnover of its capital chain, which will then cause the break of the capital chain of the enterprise, make the enterprise have financial problems, and also make the daily operation into a dilemma.

\section{Countermeasures of centralized purchasing management in China's chain retail enterprises}

\subsection{Establishment of distribution center}

Establish a distribution center close to the store or where urban transportation is convenient. All goods purchased from the manufacturer shall be transported to the distribution center for storage. This method is conducive to solving the problem that goods cannot be supplied in time. Although warehousing is increased, its efficiency is improved. Therefore, as long as the later management level is improved and optimized, the cost saved will surely exceed the cost of warehousing.

\subsection{Establish an information sharing platform based on Internet technology}

This method is mainly aimed at suppliers who have been cooperating with enterprises for a long time and are relatively stable. At present, the rapid development of Internet technology provides strong technical support for chain retail enterprises, making the in-depth transformation of supply chain possible. By establishing a Shared network platform, enterprises can share information about inventory, sales volume and supply of different products with suppliers. In this way, suppliers can know the sales volume of their products and facilitate their upgrading and adjustment of production plans.

\subsection{Strictly select suppliers and purchase channels}

In the selection of purchase channels and suppliers need to be more assessment, set the assessment period, if through re-finalization become a partner. In addition, we can try to file the supplier. Each supplier should record the product category, business status, brand reputation, market share and other information in detail. After archiving the information, the supplier should be updated timely according to the supplier's own situation, so as to understand the daily trend of the supplier, which is not only conducive to the quality of goods, but also conducive to the selection of qualified suppliers. For a retail enterprise, qualified and honest suppliers are crucial to the future development of the enterprise. 


\subsection{Establish and improve management mechanism to meet the requirements of centralized procurement}

Enterprises need to make efforts to improve the management level of procurement and unify the caliber to standardize and standardize the whole procurement process and improve the operation efficiency. At the same time, the company separates management, procurement and logistics. The whole commodity supply chain should not only be interconnected but also supervise each other to provide systematic organization guarantee for centralized procurement.The company also needs to establish various supervision systems for procurement, avoid high-risk events in the enterprise, improve the efficiency of enterprise procurement management and storage supply, and enhance the core competitiveness of the enterprise.

\section{Reference}

[1] lu xiaoqing. From centralized procurement management to supply chain management -discussion on the intensive procurement management strategy path of state grid corporation of China [J]. Zhejiang economy.2016.18

[2] zheng jianhong. Discussion on ways to improve the level of enterprise procurement risk management $[\mathrm{J}]$. Economic and trade practice.2015.06

[3] qi zhiping. Necessity and countermeasures for construction enterprises to carry out centralized material procurement management [J]. Doors and Windows,2015.04

[4] ding yingqi. Discussion on modern enterprise material purchase management [J]. Management and technology of small and medium-sized enterprises.2017.02

[5] jia qing. Thoughts on enterprise centralized procurement [J]. Management. January, 2017

[6] jiahui, gao ruixia. Bai qiying. There are rules for centralized procurement of production materials [J]. China cooperative economy, 2015.10

[7] wang xiaoyun. A brief discussion on centralized procurement and risk control of enterprise materials [J]. Shenhua technology.2018.06

[8] lu mingwei. Zhang jun. Chen huaiyi. Management of state-owned enterprise material procurement [J]. Modern enterprise culture.2014.09

[9] Yang quansheng. Wang jian. On how to improve centralized procurement management [J]. Research on modern state-owned enterprises. March, 2017

[10]Lars Erik Gadde.Finn Wynstra. Purchasing management and the role of uncertainty[J].IMP Journal.2018.01 